\title{
Shaping the future of migraine targeting Calcitonin-Gene-Related-Peptide with the Disease-Modifying Migraine Drugs (DMMDs)
}

\author{
Paolo Martelletti ${ }^{1 *}$ (D) Lars Edvinsson ${ }^{2}$ and Messoud Ashina $^{3}$
}

Speaking of a new pharmacological class, which includes the monoclonal antibodies for Calcitonin Gene Related Peptide or its receptor (CGRP (r)) and gepants seems to be a simple thing, given the enormous expectation that has arisen around them and the enormity of data that we have seen. The numerous randomized control trials (RCTs) of the four siblings, erenumab, fremanezumab, galcanezumab, eptinezumab, show strong evidence for their differentiated use in episodic, chronic and refractory migraine, as second-line drugs for now $[1,2]$. Even studies on gepants are moving, albeit with differentiated speed, in the area of prevention or acute treatment of migraine. We have on the horizon the reappearance of a pharmacological class composed of atogepant, rimegepant and ubrogepant [3] (Fig. 1).

We now have recommendations from the European Headache Federation on the use of monoclonal antibodies that will act as a guide and as a beacon in the coming years to be regularly updated as new scientific evidences will be available [4].

The CGRP( $\mathrm{r}$ ) target in migraine has solid retrospective roots, moving its first steps in the world of the trigeminovascular system of CGRP over 30 years ago, when it was demonstrated that the perivascular administration of the powerful vasoconstrictor, norepinephrine, produced the spontaneous counteract dilation response of CGRP [5, 6]. This was coined trigeminovascular reflex, aborted by lesions of the trigeminal nerve.

Subsequent work revealed that CGRP was the neuronal responsible messenger [7].

\footnotetext{
* Correspondence: paolo.martelletti@uniroma1.it

${ }^{1}$ Department of Clinical and Molecular Medicine, Sapienza University, Rome, Italy

Full list of author information is available at the end of the article
}

The journey then had several stages, and the caravan was always enriched with new data, up to the current stage we celebrate today, a new pharmacological target dedicated to migraine and based on monoclonal antibodies directed against either CGRP or the CGRP receptor or on small molecules with antagonism activity towards the CGRP $[1,8]$.

Interfering with the important release of CGRP at the level of neurons and fibers of the Trigeminal Ganglion (TG), activated by the still unknown natural switch-on originating putatively in the Central Nervous System (migraine generator), CGRP (r) Mabs are the most recent drug barrier able to tackle migraine pain onset $[1,2]$.

Translational medicine has then transferred this basic science research data to the human science, setting-up an experimental human migraine model leading to novel vascular mechanics insights as well as neuroimaging studies through the use of functional MRI (fMRI) blood oxygenation level dependent (BOLD) revealing that CGRP acts outside the Blood-Brain-Barrier (BBB) [9].

The necessity to have these drugs now available for patients opens a new phase, stimulates new studies and generates the expectation of real-world data. In the meantime, we must consider that the clinical application of these drugs directed to the CGRP, members of the first and only pharmacological classes created de novo for migraine treatment, acting on the CGRP biomarker of disease [10], maintain their long-term efficacy reverting this way the migraine disease to a quasi-silent state [11].

With these premises, we can define this CGRP new pharmacological class as Disease-Modifying-Migraine-Drugs (DMMDs), for the benefit of the huge number of patients needing therapies that, if promptly used, can slow down or freeze or revert the natural course of migraine [12]. 

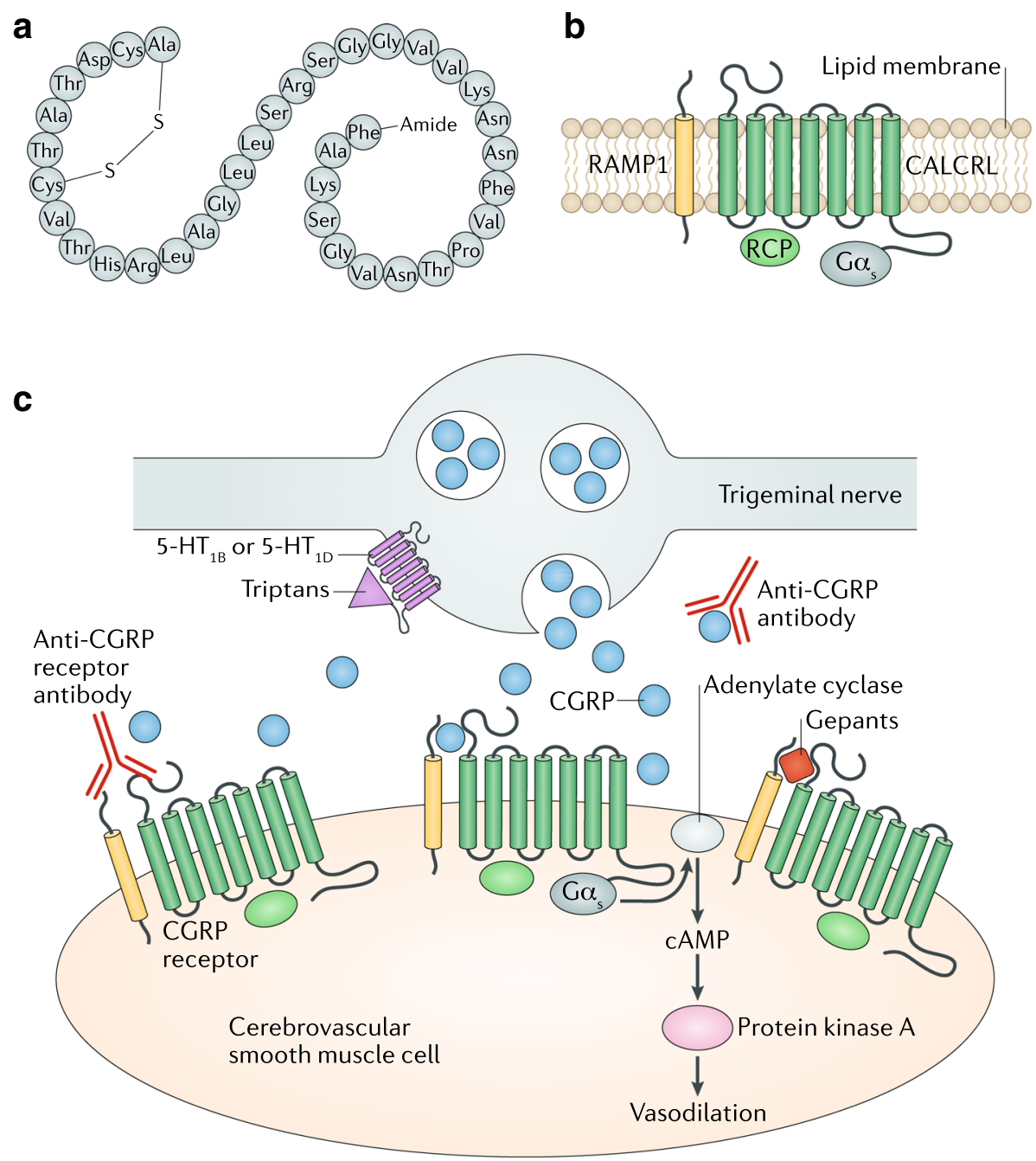

Nature Reviews | Neurology

Fig. 1 The overall picture on how the new era of CGRP pathway interacting molecules is given below. These drugs are designer molecules that have been constructed as anti-migraine [1]

Only in this way will we be able to respond to an ever more evident cultural movement that, based on scientific data, wants to categorize migraine not as an ineluctable family trace but as an endemic disease, which represents one of the major public health priorities worldwide [13, 14].

\section{Acknowledgements}

All the Authors contributed equally to the preparation of this Editorial. They declare no competing interests.

\section{Funding}

The APCs (article processing charges) for the articles in this thematic series The Changing faces of migraine' were made possible through independent educational sponsorship by Eli Lilly. Eli Lilly provided the funds through an educational grant which included enduring materials within the context of a symposium at the 12th European Headache Federation Congress in September 2018, chaired by Paolo Martelletti. This grant was provided to Springer Healthcare IME who organized the symposium and all of the enduring materials. Three of the articles in this thematic series were developed from content presented at the symposium. Eli Lilly were not involved in the planning of the thematic series, the selection process for topics, nor in any peer review or decision-making processes.

The articles have undergone the journal's standard peer review process overseen by the Editor-in- Chief. For articles where the Editor-in-Chief is an author, the peer review process was overseen by one of the other Editors responsible for this thematic series.

Availability of data and materials

-Not Applicable.

\section{Authors' contributions}

All authors read and approved the final manuscript.

Ethics approval and consent to participate

-Not Applicable.

Consent for publication

-Not Applicable. 


\section{Competing interests}

-Not Applicable.

\section{Publisher's Note}

Springer Nature remains neutral with regard to jurisdictional claims in published maps and institutional affiliations.

\section{Author details}

'Department of Clinical and Molecular Medicine, Sapienza University, Rome, Italy. ${ }^{2}$ Department of Clinical Sciences, Lund University, Lund, Sweden. ${ }^{3}$ Department of Neurology and Danish Headache Center, University of

Copenhagen, Copenhagen, Denmark.

Received: 12 April 2019 Accepted: 30 April 2019

Published online: 23 May 2019

\section{References}

1. Edvinsson L, Haanes KA, Warfvinge K, Krause DN (2018) CGRP as the target of new migraine therapies - successful translation from bench to clinic. Nat Rev Neurol 14(6):338-350

2. Ashina M (2019) The most important advances in headache research in 2018. Lancet Neurol 18(1):5-6

3. Martelletti P, Giamberardino MA (2019) Advances in orally administered pharmacotherapy for the treatment of migraine. Expert Opin Pharmacother 20(2):209-218

4. Sacco S, Bendtsen L, Ashina M, Reuter U, Terwindt G, Mitsikostas DD, Martelletti P (2019 Jan 16) European headache federation guideline on the use of monoclonal antibodies acting on the calcitonin gene related peptide or its receptor for migraine prevention. J Headache Pain. 20(1):6

5. Edvinsson L (2018) CGRP antibodies as prophylaxis in migraine. Cell. 175(7):1719

6. McCulloch J, Uddman R, Kingman TA, Edvinsson L (1986) Calcitonin generelated peptide: functional role in cerebrovascular regulation. Proc Natl Acad Sci U S A 83(15):5731-5735

7. Edvinsson L, Jansen I, Kingman TA, McCulloch J (1990) Cerebrovascular responses to capsaicin in vitro and in situ. Br J Pharmacol 100(2):312-318

8. Lambru G, Andreou AP, Guglielmetti M, Martelletti P (2018 Nov 28) Emerging drugs for migraine treatment: an update. Expert Opin Emerg Drugs. https://doi.org/10.1080/14728214.2018.1552939

9. Ashina M, Hansen JM, Á Dunga BO, Olesen J (2017) Human models of migraine - short-term pain for long-term gain. Nat Rev Neurol 13(12):713-724

10. Fan PC, Kuo PH, Lee MT, Chang SH, Chiou LC (2019) Plasma calcitonin gene-related peptide: a potential biomarker for diagnosis and therapeutic responses in pediatric migraine. Front Neurol 10:10. https://doi.org/10.3389/ fneur.2019.00010 eCollection 2019

11. Ashina M, Dodick D, Goadsby PJ, Reuter U, Silberstein S, Zhang F, Gage JR, Cheng S, Mikol DD, Lenz RA (2017) Erenumab (AMG 334) in episodic migraine: interim analysis of an ongoing open-label study. Neurology. 89(12):1237-1243

12. Martelletti $P$ (2017) The application of CGRP( $r$ ) monoclonal antibodies in migraine Spectrum: needs and priorities. BioDrugs. 31(6):483-485

13. GBD 2016 Headache Collaborators (2018) Global, regional, and national burden of migraine and tension-type headache, 1990-2016: a systematic analysis for the Global Burden of Disease Study 2016. Lancet Neurol 17(11):954-976

14. Steiner TJ, Stovner LJ, Vos T, Jensen R, Katsarava Z (2018) Migraine is first cause of disability in under 50s: will health politicians now take notice? J Headache Pain 19(1):17

Ready to submit your research? Choose BMC and benefit from:
- fast, convenient online submission
- thorough peer review by experienced researchers in your field
- rapid publication on acceptance
- support for research data, including large and complex data types
- gold Open Access which fosters wider collaboration and increased citations
- maximum visibility for your research: over 100M website views per year
At BMC, research is always in progress.
Learn more biomedcentral.com/submissions

